DOI: 10.12731/2070-7568-2021-10-3-125-141

УДК 336.225

\title{
НАЛОГОВОЕ АДМИНИСТРИРОВАНИЕ ЛИЦЕНЗИРУЕМЫХ ВИДОВ ПРЕДПРИНИМАТЕЛЬСКОЙ ДЕЯТЕЛЬНОСТИ В КОНТЕКСТЕ ЦИФРОВИЗАЦИИ ЭКОНОМИКИ
}

\author{
Ахмадеев Р.Г., Голубцова Е.В., Калимуллина О.В.
}

Практика налогообложения игорного бизнеса за последние 20 лет в Российской Федерации претерпевала значительные изменения как с правовой конструкции, посредством выстраивания четко сформулированных подходов и определения понятийного аппарата, так и четко определенной фискальной заинтересованностью на уровне региональных бюджетов. Вместе с тем далеко неоднозначное отношение бизнеса к рассредоточению игорной деятельности по территориям страны постепенно привело к падению в абсолютных показателях соответствующих доходов бюджетов субъектов РФ за налоговые периоды 2018-2020 г2. Одним из основных преимуществ по налогу на игорный бизнес является единственный на текущий момент времени, применяемый фискальный режим в отношении хозяйствующих субъектов - организаций, и приближенный к аналогичной модели взимания отмененного с 2021 года сnецииального режима по ЕНВД. С учетом неоднозначного действия законодательства в практическом применении по налогу на игорный бизнес, в большей степени связанного с развитием циифровых технологий, перемещением потенциальных объектов обложения в мировое интернет пространство, появлением блокчейн-казино, онлайн-ресурсов по ставкам на спортивные мероприятия, необходимым аспектом совершенствования по данному налогу является актуализация основных его элементов, учитывающих современные экономические тенденции. В свою очередь действующий опыт введения прямого запрета посредством установления нормативных 
актов не позволяет в полной мере приостановить распространение нелегальной сферы контента игорного бизнеса. С учетом его дальнейшего масштабировании в мировом интернет пространстве и развитием уровня циирровых технологий, отечественной налоговой системе необходим качественно иной уровень администрирования, основанный на выстраивании фискальных взаимоотношениях не только внутри страны, но и с потенциальными зарубежными налогоплательщиками.

Ключевые слова: налогообложение; игорная деятельность; экономика; ичировые технологии; налог на игорный бизнес; предпринимательство

\section{TAX ADMINISTRATION \\ OF LICENSED BUSINESS ACTIVITIES IN THE CONTEXT OF DIGITALIZATION OF THE ECONOMY}

\section{Akhmadeev R.G., Golubtsova E.V., Kalimullina O.V.}

The practice of taxation of gambling business in the last 20 years in the Russian Federation has undergone significant changes both from the legal structure. Also through the construction of clearly articulated approaches and definition of the conceptual apparatus, the allocation of fiscal withdrawal at the level of regional budgets took place. The far ambiguous attitude of business to the dispersal of gambling activities across the territories of the country has gradually led to a fall in the absolute figures of the corresponding revenues of the budgets of the subjects of the Russian Federation for the tax periods 2018-2020. One of the main advantages of the tax on gambling business is the only fiscal regime currently applied to business entities - organizations, and close to a similar model of levying the special regime for UTII, abolished since 2021. It should be noted the ambiguity in the practical application of the legislation on gambling tax, largely due to the development of digital technologies, the movement of potential objects of taxation in the global Internet space, the appearance of blockchain casinos, online resourc- 
es for betting on sporting events. An important aspect of improvement on this tax is the actualization of its main elements, taking into account current economic trends. The current experience of introducing a direct prohibition through the establishment of regulations does not allow to fully stop the spread of illegal gambling content. On the basis of such scaling in the global Internet space and the development of digital technologies, a qualitatively different level of administration is needed for the domestic tax system. It should be based on building fiscal relations not only within the country, but also with potential foreign taxpayers.

Keywords: taxation; gaming; economy; digital technology; gaming tax; entrepreneurship

\section{Введение}

Налоги и сборы являются мощным экономическим инструментом, с помощью которых реализуется проводимая бюджетная политика государства посредством изъятия на безвозмездной основе в целях обеспечения деятельности государства. Действующая модель налоговой системы Российской Федерации, основанная на плановых и фактических оценках фискальных обязательств хозяйствующих субъектов, не учитывает в должной степени особенности ведения предпринимательской деятельности для отдельных категорий плательщиков $[10,13]$. В данном случае речь идет о субъектах малого и среднего предпринимательства, поскольку установление для них особого порядка фискальных изъятий многими экономистами противоречит принципу нейтральности налогообложения. Вместе с тем налоговые преференции для этого сектора экономики в международной практике налогообложения осуществляются по большей мере для получения компенсации от проводимой государственной политики в качестве поощрения из-за сложности в расширенном банковском кредитовании, недостаточных оборотных средств и т.д.

С 2021 года в Российской Федерации для сектора малого бизнеса также был отменен специальный режим ЕНВД, основанный на условно-расчетном исчислении фискальных обязательств, что гарантировано обеспечивало поступления в бюджет в течении более 
20 лет, с учетом минимальных затрат на его администрирование. Вместе с тем аналогичные вида режимы функционируют в мировой практике по большей мере основанных на принципе «forfeit». Действующая практика применения упрощенных схем обложения налогами как правило основывается не только на факторном анализе и контроле динамических показателях деятельности субъектов, учитывая объем полученного дохода, численность сотрудников, но и отраслевую специфику и сферу их деятельности [2]. При расчете налоговой базы как правило используется оценка потенциальной величины дохода, с учетом максимального и минимального пороговых значений, а также установление величины необлагаемого минимума, льготных ставок и т.д. Действующая в отечественной практике система налогообложения для плательщиков - организаций содержит единственно возможный к практическому использованию режим обложения, основанный на принципе «forfeit» только в отношении игорной деятельности. С одной стороны, поступления по игорному бизнесу положительно влияют на общую ситуацию в экономике, обеспечивая стабильные доходы бюджетов всех уровней. А с другой, являются негативным аспектом по отношению к обществу, социальной жизни. Кроме того, в отдельных странах различными способами пытаются ограничить деятельность игорного бизнеса, используя различные фискальные инструменты, включая повышенные ставки обложения полученных доходов, выигрышей, лотерей и т.д.

До 1999 года налог на игорный бизнес не взимался, а прибыль игорных заведений облагалась по ставке 90\%. Но несмотря на высокую ставку, огромное количество налогоплательщиков этой категории и их значительные доходы поступления в бюджет были крайне низкими $[1,5]$. Применяемый впоследствии в налоге на игорный бизнес, принцип вмененного дохода себя оправдал. Налогоплательщики стали рассчитывать сумму платежа исходя из условно определенного дохода, что обеспечивало государству стабильные поступления в бюджет [8]. Дальнейшее глобальное снижение доли налога на игорный бизнес в доходах консолидированного бюджета связано 
с запретом этой деятельности вне специально отведенных зон [7]. Однако принцип вмененного дохода сохранен как единственно используемый в отечественной налоговой системе. Новые вызовы налоговому администрированию создает интернет пространство, в которой последнее время перешел этот прибыльный бизнес. К сожалению, действующий подход по налогообложению игорной деятельности в Российской Федерации не является в достаточной степени масштабируемым и привлекательным для его распространения на иные сферы предпринимательства, что обусловливает необходимость исследования данного аспекта.

\section{Материалы и методы исследования}

Целью научно-практического исследования является выявление особенностей по налогообложению игорного бизнеса для разработки оптимального подхода формирования налоговых поступлений, с учетом современных тенденций в цифровой экономике. В процессе проведения исследования применены сравнительный анализ, системный и формально-юридический подходы на основе действующего законодательства Российской Федерации. Статистический анализ проведен с использованием способа цепных подстановок в отношении сформированных по данным ФНС России сведений по налогу на игорный бизнес за налоговые периоды 2012-2020 гг.

\section{Результаты исследования}

В историческом аспекте страны в большей степени облагали игорный бизнес повышенными ставками налогов. Однако данный вид ограничений не столько снижал предпринимательскую активность бизнеса, сколько уводил его в теневой сектор экономики. В этой связи снижались рычаги и инструменты по оказанию влияния и регулирования со стороны контролирующей функции государства. Следует выделить, что до 2009 года игорный бизнес в стране являлся легализованной сферой, однако деятельность игорных заведений в совокупности с несовершенством правовой и законодательной базы приводили к возникновению существенных бюджетных потерь [6]. 
Так, установление игорных зон, призванных своим появлением ликвидировать явление стихийности игорных заведений, на остальной территории страны характеризовалось режимом незаконного ведения предпринимательской деятельности, за исключением отдельно выделенных территорий.

Вместе с тем действовавший механизм прямого налогообложения являлся неэффективным по причине сокрытия плательщиками фактического размера налоговой базы, исчисляемой в абсолютной величине, несмотря на то, что доходы игорных заведений облагались налогом на прибыль по максимальной ставке в размере 90\% [14]. Кроме того, предприниматели должны были уплачивать специальный лицензионный сбор и налог на имущество организаций.

На порядок более совершенный новый подход к взиманию игорного налога был введен с 2004 года введением 29 Главы Налогового кодекса, учитывающей уплату фиксированной суммы налога, приближенной к аналогичной модели взимания ЕНВД, с элементами аккордной системы обложения по принципу «Poll tax» [3]. Суть нового подхода состояла в том, что государство, учитывая невозможность полного учета полученных от игорной деятельности доходов, установило расчета налоговой базы исходя из фиксированного размера фискальных платежей, в четкой дифференциации по объектам обложения и соответствующей ставки.

Необходимо отметить, что на региональном уровне игорный бизнес установлен как один из видов предпринимательской деятельности, не предполагающий реализацию товаров, (работ, услуг), но являющий собой организацию и проведение игр азартного характера с целью получения доходов (рис. 1).

На основе проведенных исследований общее количество зарегистрированных плательщиков по горному бизнесу на 01 января 2021 года составило 483 ед., что на 17\%, чем за аналогичный период 2013 года. Существенный рост по отдельным объектам обложения налога отмечен только в отношении процессинговых центров букмекерских контор, за анализируемый период прирост составил $31 \%$ и в отношении процессинговых центров тотализаторов $-17 \%$ 
соответственно. Важным трендом налогового периода 2020 года в отечественной игровой индустрии является расширение предлагаемых онлайн-сервисов в сети интернет посредством развития сферы распространения букмекерских контор, с учетом влияния пандемии и различных ограничений на передвижение населения.

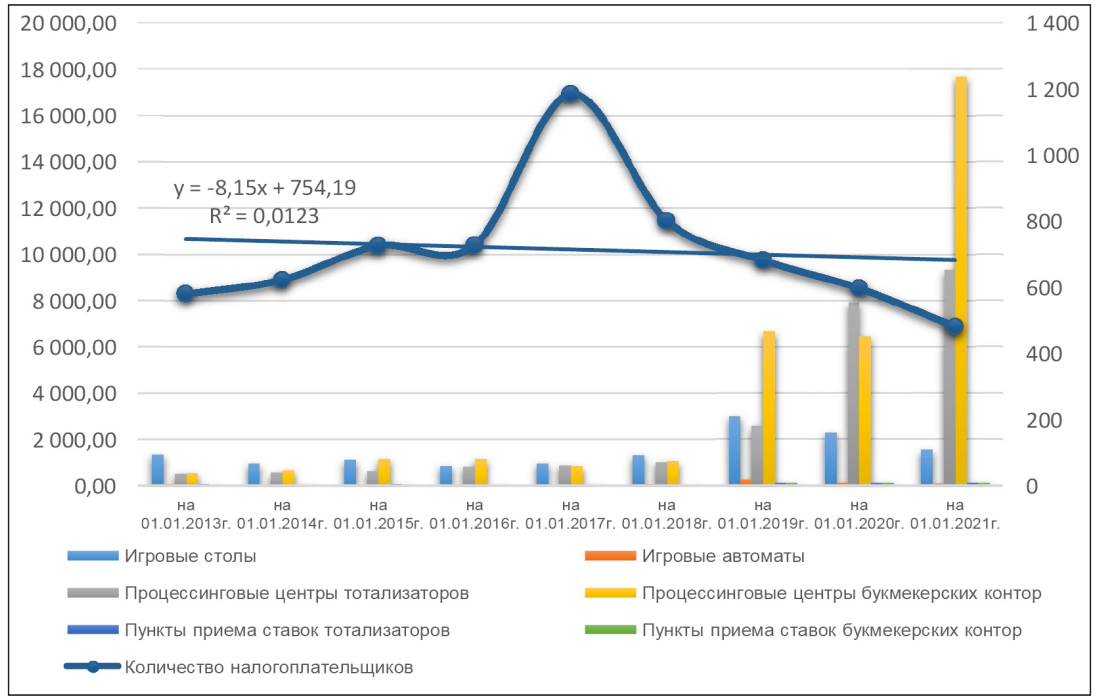

Рис. 1. Соотношение численности плательщиков и средней величины игорного налога на единицу объекта обложения по налогу на игорный бизнес, тыс. руб. (расчеты авторов проведены по данным https://www.nalog.gov.ru/rn77/related_ activities/statistics_and_analytics/forms/)

В данном случае рост поступлений по данному виду объекта обложения за налоговый период 2020 года составил 12\%. По общему подходу действующее фискальное регулирование процедуры обложения налогом игорной деятельности заключается с учетом того, что предприниматель осуществляет деятельность, подразумевающую организацию и проведения игр, носящих азартных характер на основе четко установленного перечня объектов налогообложения [9].

В рамках процесса регулирования деятельности игорных заведений государство осуществляет соответствующую деятельность, которая в полной мере раскрывается в следующих направлениях: 
1. Четкое определение регионов или отдельных территорий, в которых деятельность игорных заведений является официально разрешенной.

2. Предоставления предпринимателям лицензий на организацию и проведение азартных игр в разрешенных для этого территориях.

3. Регламентирование порядка ведения деятельности игорными заведениями, введение соответствующих видов ограничений для бизнеса, а также минимальных требований к предпринимателям, посетителям заведений, желающим принять участие и азартных играх.

4. Осуществление деятельности, направленной на обеспечение государственного контроля над деятельностью игорных заведений с целью выявления и предупреждения совершения ими противоправных деяний, нарушения положений действующего законодательства.

В том случае, если налоговые ставки не определены решением соответствующего субъекта РФ, уплата налога осуществляется в минимальном размере по каждому из объектов обложения. По общему порядку сумма налога устанавливается в зависимости от величины налоговой базы, размера определенной субъектами РФ ставки. Следует отметить, что действующим законодательством установлен порядок исчисления налога со столов, которые имеют как минимум два игровых поля, следовательно, ставка будет увеличиваться величине кратности полей стола (рис. 2).

Обсуждение. В практическом аспекте при ведении игорной деятельности предприниматели не всегда имеют возможность своевременно исполнить обязательства по уплате налога, поскольку такой принцип не увязан с фактически полученными доходами. В этом случае предусмотрено несколько форм изменения срока его уплаты. Срок уплаты может переноситься как для всей суммы налога, так и для его части. Что касается форм изменения конечной даты уплаты средств, то они могут являть собою простую отсрочку или в форме специального вида кредита, рассрочку или иной метод, применение 
которого ведет к начислению процентов на неуплаченную предпринимателем сумму. Изменять сроки могут только налоговые органы при обращении владельца игорных объектов.

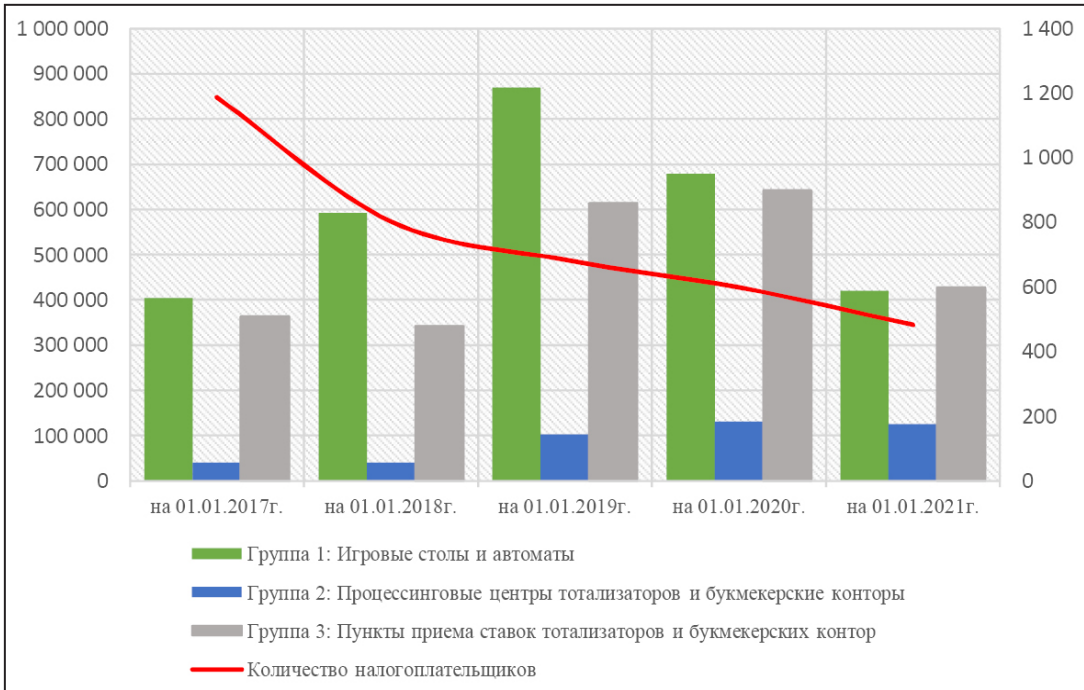

Рис. 2. Соотношение численности плательщиков и поступлений по игорному налогу, сгруппированных по группам объектов обложения, тыс. руб. (расчеты авторов проведены по данным https://www.nalog.gov.ru/rn77/related_activities/ statistics_and_analytics/forms/)

В отношении особенностей по регистрации объектов, используемых в игорном бизнесе, важным является ее осуществление при подаче предпринимателем заявления по утверждённой форме в территориальную инспекцию. Заявление должно подаваться предпринимателем в течении двух суток после установки игорного объекта, который будет использоваться в деятельности. Вместе с тем положения налогового законодательства четко не определяют момент формирования обязанности, в соответствии с которой осуществляется уплата налога по игорной деятельности [4]. По причине существования неоднозначности возникает достаточно много споров и конфликтов по поводу того, как именно необходимо определять момент возникновения обязательства. Здесь нужно указать на то, 
что налоговые органы придерживаются общего подхода, согласно которому уплата налога должно производится с момента передачи заявления о регистрации объекта, даже если в дальнейшем он не используется в бизнесе.

На основе действующей арбитражной практики необходимо выделить следующие налоговые аспекты. Неполучение прибыли от объекта по причине его неиспользования и отсутствия факта установки не является основой для возникновения обязательств по исчислению налога на игорный бизнес в силу его специфики. Тем не менее, на основе положений гражданского законодательства для лиц, осуществляющих предпринимательскую деятельность, подразумевается систематическое получение доходов. При этом, если объект игорного бизнеса не функционирует, то можно предположить, что лицо не ведет игорную деятельность и не может расцениваться как плательщик налога.

Следует отметить, что при установке игровых объектов на территории помещения налогоплательщик должен понимать, что в любой момент контролирующие органы могут потребовать уплаты налога, в том числе и с объектов, которые по факту не используются по прямому назначению. Если в процессе эксплуатации объект обложения предусматривает ремонтные работы, в этом случае уплата налога осуществляется на основании фактического количества зарегистрированных объектов, с учетом тех, которые находятся в ремонте или установлены в качестве замены и т.д. Таким образом, наличие неработающих объектов не влияет на порядок исчисления налога по игорной деятельности. Следовательно, процесс прекращения объекта налогообложения и его функционирования должен в обязательном порядке регистрироваться в налоговом органе. В ином случае обложение налогом приостановление не подлежит.

Важным практическим аспектом по осуществлению контролирующей функции игорной деятельности является право на проведение детального осмотра помещения, с учетом выявления и использования незарегистрированных объектов обложения. Данный вид контроля проводится налоговыми органами с привлечением 
подразделений МВД России, при выявлении соответствующих нарушений принимаются меры для привлечения владельца бизнеса к ответственности [11]. Данный вид нарушения соответствует величине в размере трех ставов налога, а при повторном нарушении подлежит двукратному увеличению. Следует отметить, что уплачивать налог с объектов, которые не установлены и не прошли регистрацию не требуется, при этом плательщику необходимо представить фактические доказательства о неиспользовании соответствующего объекта [12]. При этом установка объекта являет собою не только размещение на территории, а целенаправленное его установление в определенной позиции и таком положении, которое позволяет использоваться его для ведения азартных игр и получения прибыли в дальнейшем.

\section{Заключение}

В рамках деятельности игорного бизнеса на сегодняшний день существует достаточно иных спорных моментов, в частности, порядок определения для целей налогообложения детских игровых автоматов, в которых можно выиграть игрушку, как игровой объект. По действующим правилам такие автоматы определены как игорные объекты. Кроме того, игорный бизнес может основываться путем использования электронных SMS-сообщений. В этом случае не имеется специального оборудования, выделенного места объекта обложения и данный вид операций не признается игорной деятельностью.

С учетом неоднозначности практических аспектов, в большей степени связанных с развитием цифровых технологий, перемещением потенциальных объектов обложения в интернет пространство, необходимым аспектом совершенствования по игорному налогу является актуализация основных его элементов, с учетом сложившихся экономических условий текущего времени. Кроме того, в связи с влиянием пандемии, за период 2020-2021 гг. в большей степени повлияло на международное расширение сервисов облачного гейминга, распространение в практике онлайн платформ, серверы которых имеют соответствующие лицензии, например, выданные Кюрасао 
(Королевство Нидерландов). При этом нерезиденты получают значительные суммы денежных средств при продвижении электронных игр в интернет пространстве, в том числе через деятельность блокчейн-казино, онлайн-ресурсов по ставкам на спортивные мероприятия, не регистрируясь в качестве плательщиков в российской юрисдикции, соответственно без уплаты налога. Основная сложность данного вида контроля связана с возможностью технического обхода на основе интернет-плагинов, VPN и Tor браузеров. В свою очередь выплата стоимости выигрышей лицам осуществляется в биткоинах или иной цифровой валюте, данный порядок не урегулирован налоговым законодательством по НДФЛ. Следовательно, введение прямых запретительных методов на основе действующих законодательных актов не позволяет в полной мере приостановить распространение нелегальной сферы контента игорного бизнеса, с учетом дальнейшего его масштабировании в мировом интернет пространстве и развитием уровня цифровых технологий.

\section{Список литературы}

1. Абазехова 3.И. История уголовно-правового противодействия азартным играм в России // Евразийский юридический журнал. 2019. № 10 (137). С. 199-201.

2. Бобошко Н.М., Разуваева А.О. Анализ схем уклонений от уплаты налога на игорный бизнес как инструмент совершенствования методики противодействия незаконной предпринимательской деятельности // Вестник экономической безопасности. 2020. № 1. С. 236-243.

3. Бородкина Т.Н., Самолаева Е.Ю. Индустрия азартных игр: проблемы законного регулирования деятельности // Вестник экономической безопасности. 2021. № 2. С. 75-78.

4. Бочаров С.Н., Казаков С.В. Проблемные вопросы административной ответственности за незаконную организацию и проведение азартных игр // Вестник Московского университета МВД России. 2017. № 4. C. 171-175.

5. Гаглоева Э.Н., Сиукаева М.Р. Основные направления развития налоговой политики РФ // Аудиторские ведомости. 2021. № 2. С. 122-124. 
6. Дадалко В.А., Файзуллина А.А. Влияние теневой экономики в сфере туризма на экономическую безопасность Краснодарского края // Национальные интересы: приоритеты и безопасность. 2020. Т. 16, № 1 (382). С. 32-43.

7. Коваленко В.А. Актуальные проблемы исследования игорного бизнеса в России // Вопросы российского и международного права. 2019. T. 9, № 4-1. С. 20-28.

8. Корнейко О.В., Московчук Д.С., Пономарчук Н.Б., Сергеев Н.А. Оценка потенциала рынка интегрированных курортов как инструмента для экономического развития региона // Азимут научных исследований: экономика и управление. 2019. Т. 8, № 3 (28). С. 197-200

9. Кулезин М.А. Реальные проблемы виртуальных объектов // Евразийская адвокатура. 2015. № 5 (18). С. 51-53.

10. Пансков В.Г. О роли показателя налоговой нагрузки в регулировании экономики // ЭТАП: экономическая теория, анализ, практика. 2021. № 1. С. 99-110.

11. Пенькова С.Ю., Петечел Т.А. Оценка экономической и налоговой эффективности проекта игорная зона «Приморье» // Международный научно-исследовательский журнал. 2016. № 1-1 (43). С. 64-68.

12. Полярус С.А. Налог на игорный бизнес: перспективы определения объекта обложения // Налоговед. 2017. № 4. С. 36-41.

13. Пугачев А.А. Налоговые риски государства: развитие теоретических подходов в контексте актуальных проблем налоговой политики России // Налоги и налогообложение. 2021. № 1. С. 81-94.

14. Смагоринский Б.П., Евстифеева Е.П. Особенности проведения отдельных оперативно-розыскных мероприятий при выявлении и раскрытии преступлений в сфере игорного бизнеса // Вестник Волгоградской академии МВД России. 2019. № 2 (49). С. 167-173.

\section{References}

1. Abazehova Z.I. Istorija ugolovno-pravovogo protivodejstvija azartnym igram v Rossii [History of criminal law counteraction to gambling in Russia]. Evrazijskij juridicheskij zhurnal, 2019, no. 10 (137), pp. 199201. 
2. Boboshko N.M., Razuvaeva A.O. Analiz shem uklonenij ot uplaty naloga na igornyj biznes kak instrument sovershenstvovanija metodiki protivodejstvija nezakonnoj predprinimatel'skoj dejatel'nosti [Analysis of gambling tax evasion schemes as a tool to improve the methodology of combating illegal business activities]. Vestnik jekonomicheskoj bezopasnosti, 2020, no. 1, pp. 236-243.

3. Borodkina T.N., Samolaeva E.Ju. Industrija azartnyh igr: problemy zakonnogo regulirovanija dejatel'nosti [The gambling industry: problems of legal regulation of activities]. Vestnik jekonomicheskoj bezopasnosti, 2021, no. 2, pp. 75-78.

4. Bocharov S.N., Kazakov S.V. Problemnye voprosy administrativnoj otvetstvennosti za nezakonnuju organizaciju i provedenie azartnyh igr [Problematic issues of administrative responsibility for the illegal organization and conduct of gambling].Vestnik Moskovskogo universiteta MVD Rossii, 2017, no. 4, pp. 171-175.

5. Gagloeva Je.N., Siukaeva M.R. Osnovnye napravlenija razvitija nalogovoj politiki RF [Main directions of development of tax policy of the Russian Federation]. Auditorskie vedomosti, 2021, no. 2, pp. 122-124.

6. Dadalko V.A., Fajzullina A.A. Vlijanie tenevoj jekonomiki v sfere turizma na jekonomicheskuju bezopasnost' Krasnodarskogo kraja [The impact of the shadow economy in tourism on the economic security of the Krasnodar region]. Nacional 'nye interesy: prioritety i bezopasnost', 2020, vol. 16, no. 1 (382), pp. 32-43.

7. Kovalenko V.A. Aktual'nye problemy issledovanija igornogo biznesa v Rossii [Current problems of research on gambling business in Russia]. Voprosy rossijskogo i mezhdunarodnogo prava, 2019, vol. 9, no. № 4-1, pp. 20-28.

8. Kornejko O.V., Moskovchuk D.S., Ponomarchuk N.B., Sergeev N.A. Ocenka potenciala rynka integrirovannyh kurortov kak instrumenta dlja jekonomicheskogo razvitija regiona [Assessment of the potential of the integrated resorts market as a tool for economic development of the region]. Azimut nauchnyh issledovanij: jekonomika i upravlenie, 2019, vol. 8 , no. 3 (28), pp. 197-200

9. Kulezin M.A. Real'nye problemy virtual'nyh obektov [Real problems of virtual objects]. Evrazijskaja advokatura, 2015, no. 5 (18), pp. 51-53. 
10. Panskov V.G. O roli pokazatelja nalogovoj nagruzki v regulirovanii jekonomi$\mathrm{ki}$ [On the role of the tax burden indicator in the regulation of the economy]. JeTAP: jekonomicheskaja teorija, analiz, praktika, 2021, no. 1, pp. 99-110.

11. Pen'kova S.Ju., Petechel T.A. Ocenka jekonomicheskoj i nalogovoj jeffektivnosti proekta igornaja zona «Primor'e» [Assessment of economic and tax efficiency of the project Primorye Gaming Zone]. Mezhdunarodnyj nauchno-issledovatel'skij zhurnal, 2016, no. № 1-1 (43), pp. 64-68.

12. Poljarus S.A. Nalog na igornyj biznes: perspektivy opredelenija ob\#ekta oblozhenija [Tax on gambling business: prospects for determining the object of taxation]. Nalogoved, 2017, no. 4, pp. 36-41.

13. Pugachev A.A. Nalogovye riski gosudarstva: razvitie teoreticheskih podhodov v kontekste aktual'nyh problem nalogovoj politiki Rossii [Tax risks of the state: development of theoretical approaches in the context of current problems of tax policy in Russia]. Nalogi i nalogooblozhenie, 2021, no. 1, pp. 81-94.

14. Smagorinskij B.P., Evstifeeva E.P. Osobennosti provedenija otdel'nyh operativno-rozysknyh meroprijatij pri vyjavlenii i raskrytii prestuplenij v sfere igornogo biznesa [Peculiarities of individual operational and investigative measures in the detection and disclosure of crimes in the gambling business]. Vestnik Volgogradskoj akademii MVD Rossii, 2019, no. 2 (49), pp. 167-173.

\section{ДАННЫЕ ОБ АВТОРАХ}

Ахмадеев Равиль Габдуллаевич, доцент кафедры финансов и цен, к.э.н., доцент

Федеральное государственное бюджетное образовательное учреждение высшего образования «Российский экономический университет имени Г.В. Плеханова»

Стремянный переулок, 36, г. Москва, 117997, Российская Федерация

ahm_rav@mail.ru

Голубцова Екатерина Владимировна, доцент кафедры бухгалтерского учета и налогообложения, к.э.н., доцент 
Федеральное государственное бюджетное образовательное учреждение высшего образования «Российский экономический университет имени Г.В. Плеханова»

Стремянный переулок, 36, г. Москва, 117997, Российская Федерация

katarina.golubtsova@gmail.com

Калимуллина Ольга Валерьевна, доцент кафедры управления и моделирования в социально-экономических системах, к.э.н.; доцент кафедры маркетинга

Федеральное государственное бюджетное образовательное учреждение высшего образования «Санкт-Петербургский государственный университет телекоммуникаиий им. проф. М.А. Бонч-Бруевича» (СПбГУТ); Федеральное государственное бюджетное образовательное учреждение высшего образования «Санкт-Петербургский государственньй экономический университет»

пр. Большевиков, 22, корп.1, г. Санкт-Петербург, 193232, Российская Федераиия; наб. канала Грибоедова, 30-32, литер А, 2. Санкт-Петербург, 191023, Российская Федеращия chemireva@mail.ru

\section{DATA ABOUT THE AUTHORS}

Ravil G. Akhmadeev, Associate Professor in the Department of Finance and prices, British Doctor of Philosophy degree $(\mathrm{PhD})$ standard, Associate Professor

Plekhanov Russian University of Economics

36, Stremianny Pereulok, Moscow 117997, Russian Federation ahm_rav@mail.ru

ORCID: 0000-0002-7526-0144

Ekaterina V. Golubtsova, Associate Professor in the Department of Accounting and Taxation, Candidate of Economic Sciences, Associate Professor

Plekhanov Russian University of Economics 
36, Stremianny Pereulok, Moscow 117997, Russian Federation katarina.golubtsova@gmail.com

ORCID: 0000-0003-3833-2783

Olga V. Kalimullina, Associate Professor of the Department of Management and Modeling in Socio-Economic Systems, Candidate of Economic Sciences; Associate Professor of the Department of Marketing

The Bonch-Bruevich Saint-Petersburg State University of Telecommunications; St. Petersburg State University of Economics 22/1, Bolshevikov Str., St. Petersburg, 193232, Russian Federation; 30-32A, Griboyedov Canal emb., St. Petersburg, 191023, Russian Federation chemireva@mail.ru ORCID: 0000-0002-7782-6148 